\title{
Study on the Seismic Active Earth Pressure by Variational Limit Equilibrium Method
}

\author{
Jiangong Chen, ${ }^{1,2}$ Zejun Yang, ${ }^{1,2}$ Richeng Hu, ${ }^{1,2}$ and Haiquan Zhang ${ }^{1,2}$ \\ ${ }^{1}$ College of Civil Engineering, Chongqing University, Chongqing 400045, China \\ ${ }^{2}$ Key Laboratory of New Technology for Construction of Cities in Mountain Area, Chongqing University, \\ Ministry of Education, Chongqing 400045, China
}

Correspondence should be addressed to Zejun Yang; cquyzj1986@163.com

Received 8 January 2016; Revised 19 April 2016; Accepted 8 May 2016

Academic Editor: Sergio De Rosa

Copyright (C) 2016 Jiangong Chen et al. This is an open access article distributed under the Creative Commons Attribution License, which permits unrestricted use, distribution, and reproduction in any medium, provided the original work is properly cited.

\begin{abstract}
In the framework of limit equilibrium theory, the isoperimetric model of functional extremum regarding the seismic active earth pressure is deduced according to the variational method. On this basis, Lagrange multipliers are introduced to convert the problem of seismic active earth pressure into the problem on the functional extremum of two undetermined function arguments. Based on the necessary conditions required for the existence of functional extremum, the function of the slip surface and the normal stress distribution on the slip surface is obtained, and the functional extremum problem is further converted into a function optimization problem with two undetermined Lagrange multipliers. The calculated results show that the slip surface is a plane and the seismic active earth pressure is minimal when the action point is at the lower limit position. As the action point moves upward, the slip surface becomes a logarithmic spiral and the corresponding value of seismic active earth pressure increases in a nonlinear manner. And the seismic active earth pressure is maximal at the upper limit position. The interval estimation constructed by the minimum and maximum values of seismic active earth pressure can provide a reference for the aseismic design of gravity retaining walls.
\end{abstract}

\section{Introduction}

The magnitude and distribution of active earth pressure on the retaining wall under the seismic loading are the theoretical premises of the aseismic design for the retaining wall and play a vital role in evaluating the stability of the retaining wall in the seismic area. The common calculation method of seismic active earth pressure is the MononobeOkabe (M-O) theory which is based on the Coulomb theory and believes that the sliding soil wedge is a rigid body under the seismic loading. The pseudo-static approach is adopted to simplify the seismic force into an inertia force acting on the sliding soil wedge and transcribe the dynamic problem as a static problem [1]. The M-O theory assumes that the backfill behind the wall is cohesion-less soil and the slip surface is a plane, and the theory cannot obtain the real action point of resultant force without considering the equation of moment equilibrium; thus, restrictions are formed on this theory. The $\mathrm{M}-\mathrm{O}$ theory has been improved by a number of scholars to expand its application scope [2-6].
Both the M-O theory and the improvement method based thereon are on the basis of the assumption that the slip surface is a plane, which does not conform to the practical situation. One rigorous method in math is the variational limit equilibrium method, by which the seismic active earth pressure on the retaining wall is attributed as the functional extremum problem of two undetermined functions. One undetermined function is expressed by the shape of the slip surface, while the other is the function of the normal stress distribution on the slip surface. They are numerically solved by the variational method.

The variational limit equilibrium method was first proposed by Kopáscy [7-9]. Then it was introduced to the stability analysis of slope and foundation [10-22]. And some scholars utilized the variational limit equilibrium method to study the lateral earth pressure on the retaining wall [23-26]. According to the variational method, Shaojun studied the shape of the slip surface of the sliding soil wedge behind the retaining wall and obtained the analytical 
solution of the shape of the slip surface and the magnitude of seismic active earth pressure [27]. However, only the cases where the retaining wall is vertical and the backfill surface is horizontal without surcharge are considered in the calculation models, while the influences of wall-movement modes of the retaining wall on the magnitude and the action point position of seismic active earth pressure fail to be taken into account. In fact, the distribution of earth pressure on the retaining wall is nonlinear. The magnitude and the action point position of seismic active earth pressure depend on the coordinated deformation of soil-wall contact surface and vary with the change of wall-movement modes of the retaining wall [26]. However, in the design process, it is often hard to accurately estimate the wall-movement modes of the retaining wall. For the static and dynamic ultimate load acting on the retaining wall, a reasonable approach is to contain the seismic active earth pressure under different wall-movement modes in a certain range as possible for the engineering designers to select and use. In this paper, the variational limit equilibrium method is used to study the seismic active earth pressure on the gravity retaining wall under general conditions (the retaining wall is inclined and coarse; the backfill is cohesive soil; the backfill surface is a curved surface with nonuniform surcharge). The interval of the seismic active earth pressure under different wall-movement modes can be effectively estimated by the proposed approach.

\section{Variational Analysis of Seismic Active Earth Pressure}

2.1. Basic Assumption. (1) The research problem is a plane strain problem; (2) the soil behind the wall is Coulomb material, which can be represented by the intensity parameter cohesion $c$ and the internal friction angle $\varphi$; (3) when the backfill soil is in the critical active state, a sliding soil wedge is formed and its slip surface passes through the wall heel; (4) the retaining wall is rigid and its motion forms are unconstrained, wherein the motion displacement can be ignored compared with the wall height; (5) the seismic action is simplified to static load acting on the sliding wedge, with horizontal seismic coefficient $k_{H}$ and vertical seismic coefficient $k_{V}$.

2.2. Limit Equilibrium Equation of Sliding Soil Wedge. The calculation model of active earth pressure under the seismic loading is shown in Figure 1, wherein the height of the retaining wall is $H$; the retaining wall is inclined and coarse; the slope angle of the wall to vertical is $\alpha$; the friction angle between soil and wall is $\delta$; the unit weight of soil is $\gamma$; the cohesion is $c$; the internal fraction angle is $\varphi$, the expression of the backfill surface is $g(x)$, and the expression of the slip surface is $s(x)$; the expression of the vertical surcharge distribution on the backfill surface is $q(x)$, the expression of the tangential stress distribution on the slip surface is $\tau(x)$, and the expression of the normal stress distribution on the slip surface is $\sigma(x)$; the seismic soil pressure on the wall is $E_{a}$.

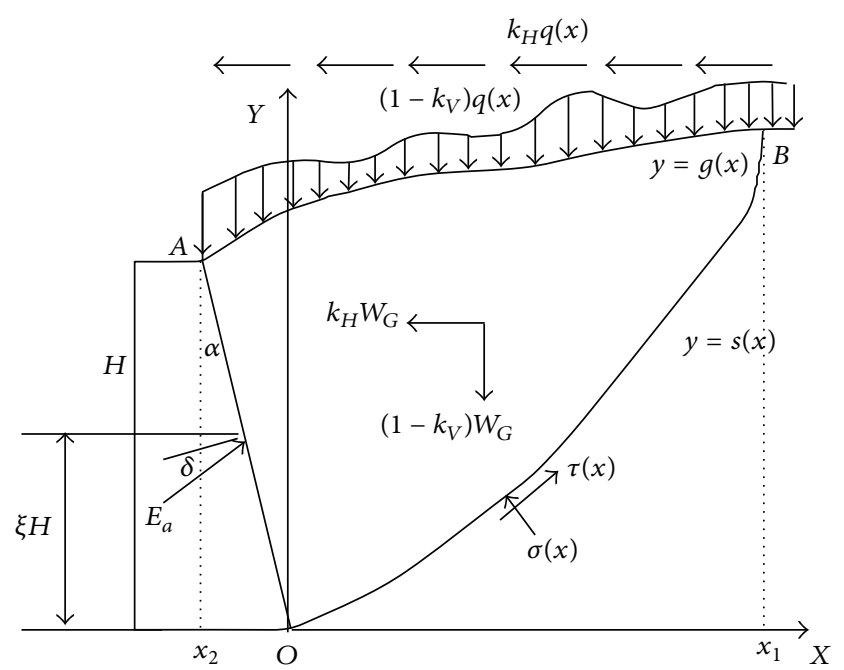

FIgURE 1: Calculation model of seismic active earth pressure.

The equilibrium equation of the sliding soil wedge $\mathrm{OAB}$ under the limit equilibrium state can be written as follows:

$$
\begin{aligned}
& E_{a} \cos (\alpha+\delta)+\int_{0}^{x_{1}} \tau-\sigma s^{\prime}-k_{H}[\gamma(g-s)+q] d x \\
& \quad-\int_{x_{2}}^{0} k_{H}[\gamma(g-k x)+q] d x=0, \\
& E_{a} \sin (\alpha+\delta)+\int_{0}^{x_{1}} \tau s^{\prime}+\sigma-\left(1-k_{V}\right)[\gamma(g-s) \\
& \quad+q] d x-\int_{x_{2}}^{0}\left(1-k_{V}\right)[\gamma(g-k x)+q] d x \\
& \quad=0, \\
& E_{a} \cos \delta \frac{\xi H}{\cos \alpha}+\int_{x_{2}}^{0}\left\{\left(1-k_{V}\right)[\gamma(g-k x)+q] x\right\} d x \\
& \quad-\int_{x_{2}}^{0} k_{H} q g d x-\int_{0}^{x_{1}} k_{H} q g d x-\int_{x_{2}}^{0} \frac{1}{2} k_{H} \gamma\left(g^{2}\right. \\
& \left.\quad-k^{2} x^{2}\right) d x-\int_{0}^{x_{1}} \frac{1}{2} k_{H} \gamma\left(g^{2}-s^{2}\right) d x \\
& \quad-\int_{0}^{x_{1}}\left\{\left(x s^{\prime}-s\right) \tau+\left(x+s s^{\prime}\right) \sigma\right. \\
& \left.\quad-\left(1-k_{V}\right)[q x+\gamma(g-s) x]\right\} d x=0,
\end{aligned}
$$

wherein $s^{\prime}=d s / d x, k=-\cot \alpha, x_{1}$ is $X$ coordinate of $B$, $x_{2}$ is $X$ coordinate of $A$, and $x_{2}=-H \tan \alpha$. $\xi$ is the position coefficient of the action point of seismic active earth pressure, and its value is the ratio of the vertical distance (from the action point position to the wall heel) to the height of the retaining wall. 
It is assumed that the tangential stress $\tau$ and the normal stress $\sigma$ on the slip surface are subject to the Mohr-Coulomb failure criterion:

$$
\tau=c+n_{1} \sigma
$$

wherein $n_{1}=\tan \varphi$.

2.3. Variational Limit Equilibrium Model of Seismic Active Earth Pressure. The problem to solve the seismic active earth pressure $E_{\mathrm{ae}}$ can now be stated as follows. The seismic active earth pressure $E_{\mathrm{ae}}$ is the maximum value of $E_{a}$, corresponding to the most dangerous (critical) slip surface. Realizing the maximum value of $E_{a}$ is to find the function of the slip surface $s(x)$ and the function of normal stress distribution $\sigma(x)$ on the slip surface, subject to the three equations of LE ((1) (3)). Among these three equations, (3) is changed as objective function and the other equations are the constraint conditions according to the variational method.

The following objective function $J$ can be obtained after (4) is substituted into (3). Obviously, to solve the maximum of $E_{a}$ means the same as to solve the maximum of objective function $J$ :

$$
J=\int_{0}^{x_{1}} F_{0} d x
$$

wherein

$$
\begin{aligned}
J= & \frac{E_{a} \xi H \cos \delta}{\cos \alpha}+z_{0}, \\
F_{0}= & \left(n_{1} s^{\prime} x+x+s s^{\prime}-n_{1} s\right) \sigma+c x s^{\prime}-c s-\left(1-k_{V}\right) \\
\cdot & {[(g-s) \gamma x+q x]+k_{H} q g+\frac{1}{2} k_{H} \gamma\left(g^{2}-s^{2}\right), } \\
z_{0}= & \int_{x_{2}}^{0}\left\{\left(1-k_{V}\right)[\gamma(g-k x)+q] x-k_{H} q g\right. \\
& \left.-\frac{1}{2} k_{H} \gamma\left(g^{2}-k^{2} x^{2}\right)\right\} d x=\text { const. }
\end{aligned}
$$

Two constraint conditions can be obtained after (4) and (5) are substituted into (1) and (2):

$$
\begin{aligned}
& \int_{0}^{x_{1}}\left(z_{1} F_{0}+F_{1}\right) d x=z_{2}, \\
& \int_{0}^{x_{1}}\left(z_{3} F_{0}+F_{2}\right) d x=z_{4},
\end{aligned}
$$

wherein

$$
\begin{aligned}
& F_{1}=\left(n_{1}-s^{\prime}\right) \sigma+c-k_{H}[\gamma(g-s)+q] \\
& F_{2}=\left(n_{1} s^{\prime}+1\right) \sigma+c s^{\prime}-\left(1-k_{V}\right)[q+\gamma(g-s)] \\
& z_{1}=\frac{\cos \alpha \cos (\alpha+\delta)}{\xi H \cos \delta}=\mathrm{const}
\end{aligned}
$$

$$
\begin{aligned}
& z_{2}=z_{0} z_{1}+\int_{x_{2}}^{0} k_{H}[\gamma(g-k x)+q] d x=\text { const, } \\
& z_{3}=\frac{\cos \alpha \cos (\alpha+\delta)}{\xi H \cos \delta}=\text { const, } \\
& z_{4}=z_{0} z_{3}+\int_{x_{2}}^{0}\left(1-k_{V}\right)[\gamma(g-k x)+q] d x=\text { const. }
\end{aligned}
$$

Equations (5) and (7) show the isoperimetric model of the constrained variational extremum with an undetermined boundary. The starting point of the slip surface $O$ is a fixed point on the coordinates of $\left(x_{0}=0, y_{0}=0\right)$ and the end point $B$ moves on the backfill surface $g(x)$ with the undetermined coordinates of $\left(x_{1}, g\left(x_{1}\right)\right)$. The undetermined boundary is a variational boundary. The variational boundary refers to an unfixed boundary on which one or two ends, respectively, move on the given function.

According to the variational method of the functional with constraints, the following auxiliary functional $J^{*}$ is constructed by Lagrange multipliers to convert the functional extremum problem under constraint conditions into a functional extremum problem without constraint conditions:

$$
\begin{aligned}
J^{*} & =\int_{0}^{x_{1}} F d x, \\
F & =F_{0}+\lambda_{1} F_{1}+\lambda_{2} F_{2},
\end{aligned}
$$

wherein $\lambda_{1}$ and $\lambda_{2}$ are Lagrange multipliers.

Now, the solution of the maximum of $E_{a}$ is converted into the solution of the maximum of auxiliary function $J^{*}$. According to the necessary conditions for the existence of the extremum of auxiliary functional $J^{*}$, the function of the slip surface $s(x)$ and the function of the normal stress distribution $\sigma(x)$ on the slip surface must meet the following requirements.

(1) The Euler differential equation of the auxiliary function $F$ is

$$
\begin{aligned}
& \frac{\partial F}{\partial \sigma}-\frac{d}{d x}\left(\frac{\partial F}{\partial \sigma^{\prime}}\right)=0 \\
& \frac{\partial F}{\partial s}-\frac{d}{d x}\left(\frac{\partial F}{\partial s^{\prime}}\right)=0
\end{aligned}
$$

(2) The integral constraint equations are (7).

(3) Boundary conditions are

Fixed boundary condition: $s(0)=0$,

Variational boundary condition: $s\left(x_{1}\right)=g\left(x_{1}\right)$.

(4) Transversality condition at the variational boundary is

$$
\left.\left(F-s^{\prime} \frac{\partial F}{\partial s^{\prime}}+g^{\prime} \frac{\partial F}{\partial s^{\prime}}\right)\right|_{x=x_{1}}=0
$$




\section{Variational Solution of Seismic Active Earth Pressure}

3.1. Shape Function of the Slip Surface. The following equation can be obtained after (5), (7), and (9) are substituted into (10):

$$
\frac{d s}{d x}=\frac{x-n_{1} s+\lambda_{1} n_{1}+\lambda_{2}}{-n_{1} x-s+\lambda_{1}-\lambda_{2} n_{1}} .
$$

Polar coordinate transformations $r \cos \theta=x+\lambda_{2}$ and $r \sin \theta=s-\lambda_{1}$ are brought in. For the calculation model in polar coordinates, see Figure 2. Equation (14) is transcribed as a differential equation:

$$
\frac{d r}{d \theta}=-n_{1} r
$$

The general solution of the differential equation is

$$
r=z_{5} e^{-n_{1} \theta}
$$

wherein $z_{5}$ is an arbitrary integration constant.

The fixed boundary condition $s(0)=0$ shows that the pole of the polar coordinate is $\left(r_{0}, \theta_{0}\right)$. After it is substituted into (16), the expression of the logarithmic spiral of the slip surface can be obtained:

$$
r=r_{0} e^{n_{1}\left(\theta_{0}-\theta\right)},
$$

wherein

$$
\begin{aligned}
r_{0} & =\sqrt{\lambda_{1}^{2}+\lambda_{2}^{2}}, \\
\theta_{0} & =-\arctan \left(\frac{\lambda_{1}}{\lambda_{2}}\right), \quad \lambda_{2}>0, \\
\theta_{0} & =-\pi-\arctan \left(\frac{\lambda_{1}}{\lambda_{2}}\right), \quad \lambda_{2} \leq 0 .
\end{aligned}
$$

3.2. Normal Stress Distribution on the Slip Surface. After (5), (7), and (9) are substituted into (11), the following equation can be obtained:

$$
\begin{aligned}
2 n_{1} \sigma & +\left(n_{1} x+s-\lambda_{1}+n_{1} \lambda_{2}\right) \sigma^{\prime}-\left(1-k_{V}\right) \gamma x \\
& -\left(1-k_{V}\right) \lambda_{2} \gamma+2 c+k_{H} \gamma s-k_{H} \lambda_{1} \gamma=0 .
\end{aligned}
$$

Introducing the Polar coordinate transformations $r \cos \theta=$ $x+\lambda_{2}$ and $r \sin \theta=s-\lambda_{1}$, (19) is transcribed as a differential equation:

$$
\begin{gathered}
\frac{d \sigma}{d \theta}-2 n_{1} \sigma=2 c-\left(1-k_{V}\right) \gamma r_{0} e^{n_{1}\left(\theta_{0}-\theta\right)} \cos \theta \\
+k_{H} \gamma r_{0} e^{n_{1}\left(\theta_{0}-\theta\right)} \sin \theta .
\end{gathered}
$$

The general solution of the differential equation is (when $n_{1} \neq$ 0)

$$
\begin{aligned}
\sigma= & e^{\int_{\theta_{1}}^{\theta} 2 n_{1} d \theta}\left(z_{6}+\int_{\theta_{1}}^{\theta}(2 c\right. \\
& \left.-\left(1-k_{V}\right) \gamma r_{0} e^{n_{1}\left(\theta_{0}-\theta\right)} \cos \theta+k_{H} \gamma r_{0} e^{n_{1}\left(\theta_{0}-\theta\right)} \sin \theta\right) \\
& \left.\cdot e^{\int_{\theta_{1}}^{\theta}-2 n_{1} d \theta} d \theta\right),
\end{aligned}
$$

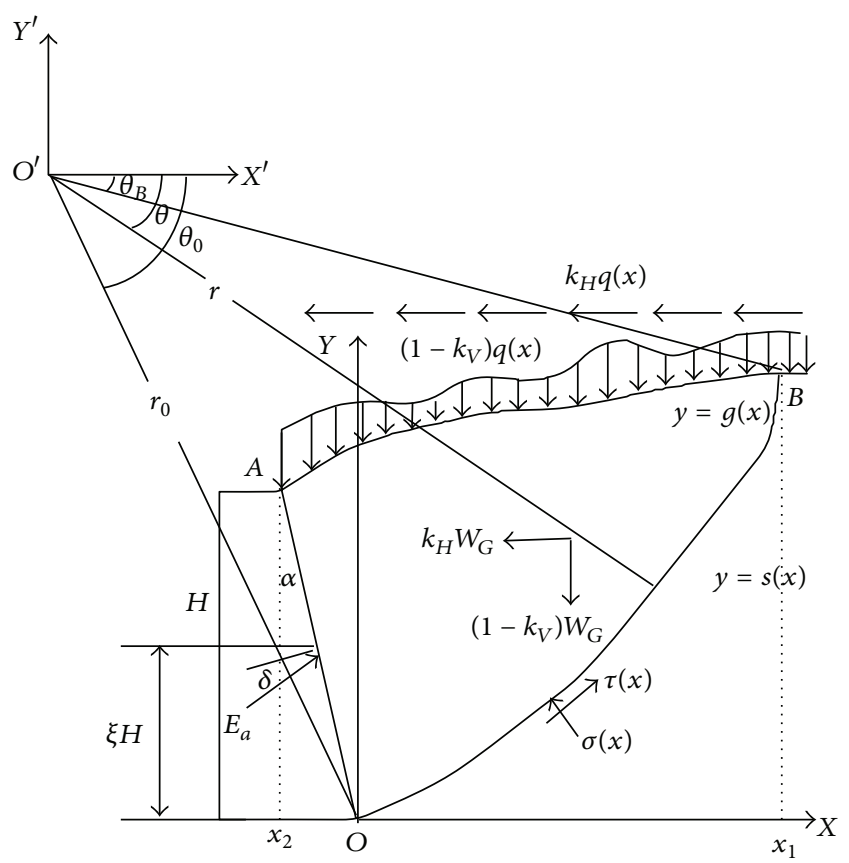

FIGURE 2: Calculation model of seismic active earth pressure in polar coordinates.

wherein $z_{6}$ is an integration constant; $\theta_{1}$ is an arbitrary angle; $\theta_{1}=0$ is available

$$
\begin{aligned}
\sigma & =z_{6} e^{2 n_{1} \theta}-\frac{\left(1-k_{V}\right) \gamma r_{0} e^{n_{1}\left(\theta_{0}-\theta\right)}}{1+9 n_{1}^{2}}\left(\sin \theta-3 n_{1} \cos \theta\right. \\
& \left.+3 n_{1} e^{3 n_{1} \theta}\right)-\frac{k_{H} \gamma r_{0} e^{n_{1}\left(\theta_{0}-\theta\right)}}{1+9 n_{1}^{2}}\left(3 n_{1} \sin \theta+\cos \theta\right. \\
& \left.-e^{3 n_{1} \theta}\right)-\frac{c}{n_{1}} .
\end{aligned}
$$

According to the transversality condition at the variational boundary, the normal stress distribution at $B$ of the slip surface can be obtained:

$$
\begin{aligned}
& \sigma\left(x_{1}\right) \\
& =\frac{\sin \theta_{1}\left(c-k_{H} q\left(x_{1}\right)\right)+\cos \theta_{1}\left[\left(1-k_{V}\right) q\left(x_{1}\right)-c g^{\prime}\left(x_{1}\right)\right]}{\sin \theta_{1}\left(g^{\prime}\left(x_{1}\right)-n_{1}\right)+\cos \theta_{1}\left(n_{1} g^{\prime}\left(x_{1}\right)+1\right)} .
\end{aligned}
$$

After it is substituted into (22), the following equation is obtained:

$$
\begin{aligned}
z_{6} & =e^{-2 n_{1} \theta_{1}}\left\{\frac{c}{n_{1}}+\frac{k_{H} \gamma r_{0} e^{n_{1}\left(\theta_{0}-\theta_{1}\right)}}{1+9 n_{1}^{2}}\left(3 n_{1} \sin \theta_{1}+\cos \theta_{1}-e^{3 n_{1} \theta_{1}}\right)\right. \\
& +\frac{\left(1-k_{V}\right) \gamma r_{0} e^{n_{1}\left(\theta_{0}-\theta_{1}\right)}}{1+9 n_{1}^{2}}\left(\sin \theta_{1}-3 n_{1} \cos \theta_{1}+3 n_{1} e^{3 n_{1} \theta_{1}}\right) \\
& \left.+\frac{\sin \theta_{1}\left(c-k_{H} q\left(x_{1}\right)\right)+\cos \theta_{1}\left[\left(1-k_{V}\right) q\left(x_{1}\right)-c g^{\prime}\left(x_{1}\right)\right]}{\sin \theta_{1}\left(g^{\prime}\left(x_{1}\right)-n_{1}\right)+\cos \theta_{1}\left(n_{1} g^{\prime}\left(x_{1}\right)+1\right)}\right\} .
\end{aligned}
$$

3.3. Optimal Solution of Seismic Active Earth Pressure. The analysis carried out so far indicates that the maximum value 
of $E_{a}$ can be obtained according to a pair of functions $r(\theta)$ and $\sigma(\theta)$ determined by two undetermined Lagrange multipliers $\lambda_{1}$ and $\lambda_{2}$. The problem is converted into the search of a pair of constants $\lambda_{1}$ and $\lambda_{2}$ through the two constraint equations. The two constraint equations-(7) - must be satisfied:

$$
\begin{aligned}
& f_{1}\left(\lambda_{1}, \lambda_{2}\right)=\int_{0}^{x_{1}}\left(z_{1} F_{0}+F_{1}\right) d x-z_{2}=0, \\
& f_{2}\left(\lambda_{1}, \lambda_{2}\right)=\int_{0}^{x_{1}}\left(z_{3} F_{0}+F_{2}\right) d x-z_{4}=0 .
\end{aligned}
$$

The following equation is always correct:

$$
\begin{aligned}
& f_{1}\left(\lambda_{1}, \lambda_{2}\right)=0 \\
& f_{2}\left(\lambda_{1}, \lambda_{2}\right)=0
\end{aligned} \Longleftrightarrow \Phi\left(\lambda_{1}, \lambda_{2}\right)=f_{1}^{2}\left(\lambda_{1}, \lambda_{2}\right)+f_{2}^{2}\left(\lambda_{1}, \lambda_{2}\right)=0 .
$$

Therefore, two integral equations-(25) - are equivalent to the following equation:

$$
\begin{aligned}
\Phi\left(\lambda_{1}, \lambda_{2}\right)= & f_{1}^{2}\left(\lambda_{1}, \lambda_{2}\right)+f_{2}^{2}\left(\lambda_{1}, \lambda_{2}\right) \\
= & {\left[\int_{0}^{x_{1}}\left(z_{1} F_{0}+F_{1}\right) d x-z_{2}\right]^{2} } \\
& +\left[\int_{0}^{x_{1}}\left(z_{3} F_{0}+F_{2}\right) d x-z_{4}\right]^{2}=0 .
\end{aligned}
$$

For $\Phi\left(\lambda_{1}, \lambda_{2}\right) \geq 0$, so

$$
\min \left[\Phi\left(\lambda_{1}, \lambda_{2}\right)\right]=0 .
$$

The above analysis indicates that the solution of the two constraint equations-(7)-can be obtained through the solution of the minimum value of the function $\Phi$ (the minimum value is 0 ). When the minimum value of $\Phi$ is not 0 , it shows that the sliding soil wedge cannot keep balance and is improper.

In this paper, the fminsearch function provided by MAT$L A B$ is used to find the optimal solution. For this function, it only requires establishing a function module of $\Phi$ and giving an initial value to search the minimum value of the function. Fminsearch applies the derivative-free method to find the minimum value of the unconstrained multivariable function, which is generally called unconstrained nonlinear optimization. Fminsearch finds the minimum of a scalar function of several variables starting at an initial estimate. Therefore, one major drawback of this optimization tool is that the search would be very slow if the initial estimate is improper. In order to overcome this drawback and in the consideration of the condition that the center of the logarithmic spiral is usually at the top left corner of the retaining wall, the initial value is $\lambda_{1}=\lambda_{2}=H$ in the optimization analysis of this paper and the search is quite rapid.

\section{Calculated Result and Parameter Analysis}

4.1. Interval Estimation of Seismic Active Earth Pressure. Under the general conditions that the retaining wall is

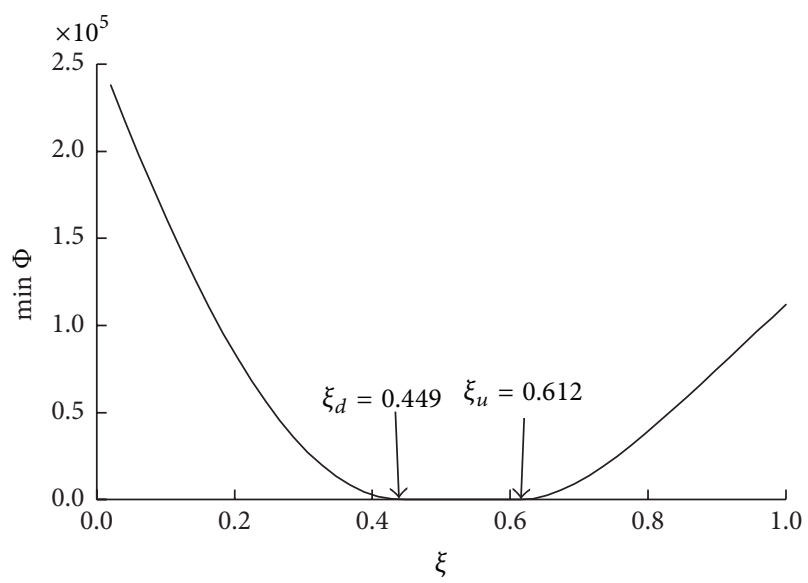

FIgURE 3: The minimum value of the function $\Phi$.

inclined and coarse, the backfill is cohesive soil, and the backfill surface is inclined with surcharge, the interval of the position coefficient $\xi$ of the action point under seismic loading is numerically solved. Besides, the influence of the action point position on the shape of the slip surface and the magnitude of seismic active earth pressure is studied.

The retaining wall has a height of $10 \mathrm{~m}$, with the slope angle of the wall to vertical $\alpha=10^{\circ}$, the friction angle between soil and wall $\delta=15^{\circ}$, the unit weight of soil $\gamma=18 \mathrm{kN} / \mathrm{m}^{3}$, cohesion $c=10 \mathrm{kPa}$, internal friction angle $\varphi=20^{\circ}$, slope angle of the backfill soil $\beta=5^{\circ}$, surcharge $q=50 \mathrm{kN} / \mathrm{m}$, and seismic coefficients $k_{H}=0.05$ and $k_{V}=0.0$.

Figure 3 shows the curve of the minimum value of the function $\Phi$ varying with the position coefficient $\xi$ of the action point. As shown in the figure, the position coefficient $\xi$ of the action point of seismic active earth pressure is in an interval (lower limit value $\xi_{d}=0.449$; upper limit value $\xi_{u}=$ 0.612 ). In the interval, the minimum value of the function $\Phi$ is 0 . In other words, when the action point of seismic active earth pressure falls within the range of $4.49 \sim 6.12 \mathrm{~m}$ from the wall bottom, the counterforce provided by the retaining wall can balance the soil mass behind the wall; otherwise, the soil mass will inevitably lose its balance no matter how big the counterforce provided by the retaining wall is.

There is a one-to-one corresponding relation between the magnitude of seismic active earth pressure and the shape of slip surface (Figure 5). For the curves varying with the position coefficient $\xi$ of the action point of seismic active earth pressure, see Figures 3 and 4 . At the lower limit of $\xi$, the slip surface is a plane, with the minimal value of seismic active earth pressure. As the action point moves upward, the slip surface becomes a logarithmic spiral surface and its curvature is gradually increased; that is, in the logarithmic spiral equation, $r_{0}$, is gradually decreased, and the corresponding value of seismic active earth pressure is increased in a nonlinear manner. At the upper limit of $\xi$, the seismic active earth pressure is maximal. The minimum and maximum values can be as an interval estimation of the seismic active earth pressure under different wall-movement modes of the retaining wall. 
TABLE 1: Comparison of calculated results of active earth pressure with that of M-O.

\begin{tabular}{|c|c|c|c|c|c|c|c|}
\hline \multirow{2}{*}{$\alpha /^{\circ}$} & \multirow{2}{*}{$\beta 1^{\circ}$} & \multirow{2}{*}{$k_{H}$} & \multirow{2}{*}{$k_{V}$} & \multicolumn{2}{|c|}{ The proposed method } & \multicolumn{2}{|c|}{ M-O method } \\
\hline & & & & $E_{\mathrm{ae}} / \mathrm{kN}$ & $\xi$ & $E_{a} / \mathrm{kN}$ & $\xi$ \\
\hline 0 & 0 & 0 & 0 & $391.0 \sim 412.1$ & $0.265 \sim 0.408$ & 391.0 & $1 / 3$ \\
\hline 0 & 5 & 0.05 & 0.05 & $424.6 \sim 450.2$ & $0.286 \sim 0.449$ & 424.5 & $1 / 3$ \\
\hline 0 & 10 & 0.1 & 0.1 & $470.8 \sim 495.0$ & $0.306 \sim 0.490$ & 470.7 & $1 / 3$ \\
\hline 10 & 0 & 0.05 & 0.1 & $460.5 \sim 475.2$ & $0.327 \sim 0.408$ & 460.1 & $1 / 3$ \\
\hline 10 & 5 & 0.1 & 0 & $504.3 \sim 525.3$ & $0.327 \sim 0.449$ & 504.3 & $1 / 3$ \\
\hline 10 & 10 & 0 & 0.05 & $559.9 \sim 572.8$ & $0.367 \sim 0.469$ & 559.6 & $1 / 3$ \\
\hline 20 & 0 & 0.1 & 0.05 & $550.4 \sim 562.8$ & $0.347 \sim 0.408$ & 550.3 & $1 / 3$ \\
\hline 20 & 5 & 0 & 0.1 & $604.9 \sim 616.1$ & $0.367 \sim 0.429$ & 604.7 & $1 / 3$ \\
\hline 20 & 10 & 0.05 & 0 & $682.7 \sim 696.3$ & $0.388 \sim 0.469$ & 682.5 & $1 / 3$ \\
\hline
\end{tabular}

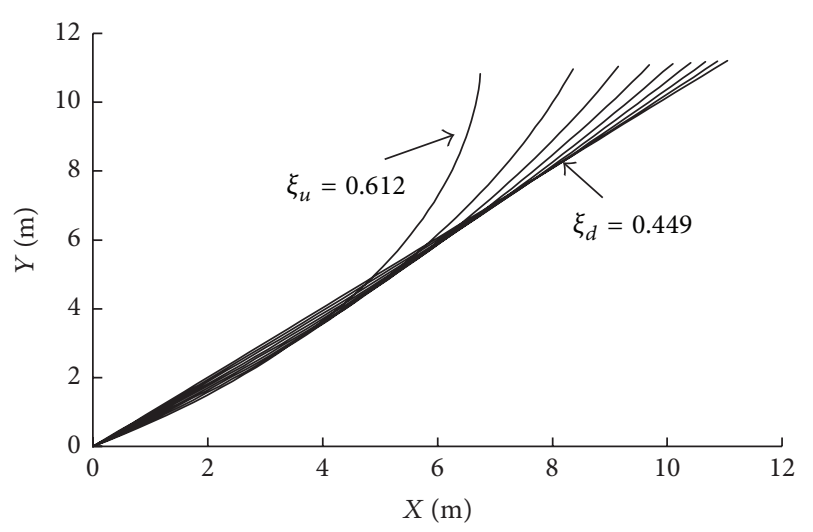

FIgURE 4: The shape of the slip surface.

4.2. Comparison with the M-O Theory Solution. To verify the correctness of the calculation method proposed in this paper, a comparison is made between the calculated result of the proposed method and the solution of M-O theory. According to the assumption of M-O theory, the values of cohesion $c$ and the surcharge $q$ are both 0 in the contrastive analysis. For other parameters and specific comparison results, see Table 1 .

When the slip surface is a plane, the seismic active earth pressure is the lower limit value of the interval in the table. This value is equivalent to the solution of seismic active earth pressure calculated by the $\mathrm{M}-\mathrm{O}$ theory. The solution obtained in the proposed method is degraded into $\mathrm{M}-\mathrm{O}$ theory solution, thereby proving the correctness of the proposed method.

When the slip surface is a logarithmic spiral surface, the seismic active earth pressure calculated by the $\mathrm{M}-\mathrm{O}$ theory is relatively small, and the assumed action point position is lower than the actual action point position under most possible wall-movement modes. The underestimation of the magnitude and the action point position of seismic active earth pressure cause the potential safety hazard of overturning of the retaining wall designed by $\mathrm{M}-\mathrm{O}$ theory.
4.3. Parameter Analysis. In this section, discussions are made regarding the influence of relevant parameters on the magnitude and the action point position of seismic active earth pressure, as well as the overturning moment on the retaining wall. Such parameters include the slope angle $\alpha$ of the retaining wall, the slope angle $\beta$ of backfill surface, the surcharge $q$ on the backfill surface, the horizontal seismic coefficient $k_{H}$, and the vertical seismic coefficient $k_{V}$.

4.3.1. Influence of Parameters on the Action Point Position. The influence of relevant parameters on the position coefficient $\xi$ of action point of seismic active earth pressure is shown in Figures 6(a)-6(c). With the increase of the slope angle $\beta$ of backfill surface, the action point position moves up; with the increase of $\alpha$, the action point position slightly moves down; with the increase of the horizontal seismic coefficient $k_{H}$ and the vertical seismic coefficient $k_{V}$, the action point position moves up, wherein the horizontal seismic coefficient $k_{H}$ has a significant influence on it; with the increase of the surcharge $q$, the action point position moves up in a nonlinear way.

4.3.2. Influence of Parameters on the Seismic Active Earth Pressure $E_{a e}$. Figures $7(a)-7(c)$ show the influence of relevant parameters on the dimensionless seismic active earth pressure $E_{\mathrm{ae}} /\left(\gamma H^{2}\right)$. The seismic active earth pressure $E_{\mathrm{ae}}$ is increased with the increase of the slope angle $\alpha$ of the retaining wall and the slope angle $\beta$ of backfill surface; $E_{\mathrm{ae}}$ is increased with the increase of the horizontal seismic coefficient $k_{H}$ and decreased with the increase of the vertical seismic coefficient $k_{V} ; E_{\mathrm{ae}}$ is increased linearly with the increase of the dimensionless surcharge $q /(\gamma H)$ of slope surface.

4.3.3. Influence of Parameters on the Overturning Moment $M_{a}$. Figures 8(a)-8(c) show the influence of relevant parameters on the dimensionless overturning moment $M_{a} / \gamma H^{3}$. The overturning moment $M_{a}$ is increased with the increase of 


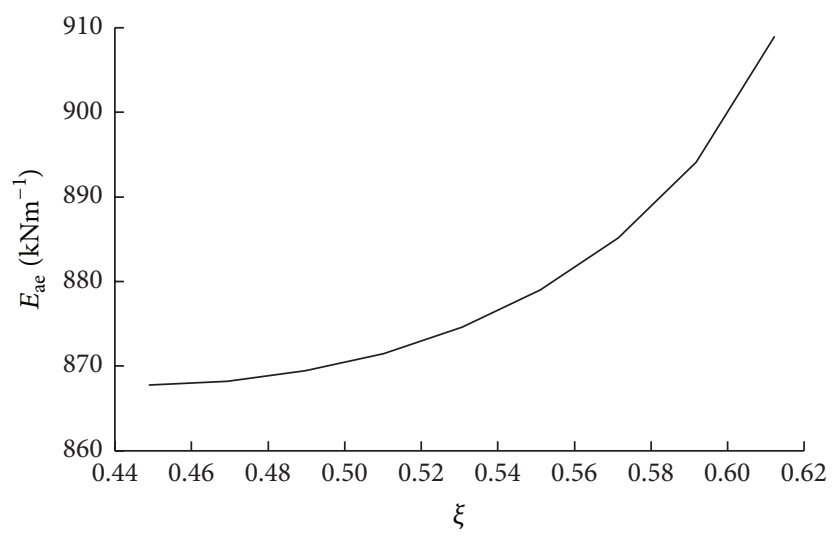

FIGURE 5: The magnitude of seismic active earth pressure.
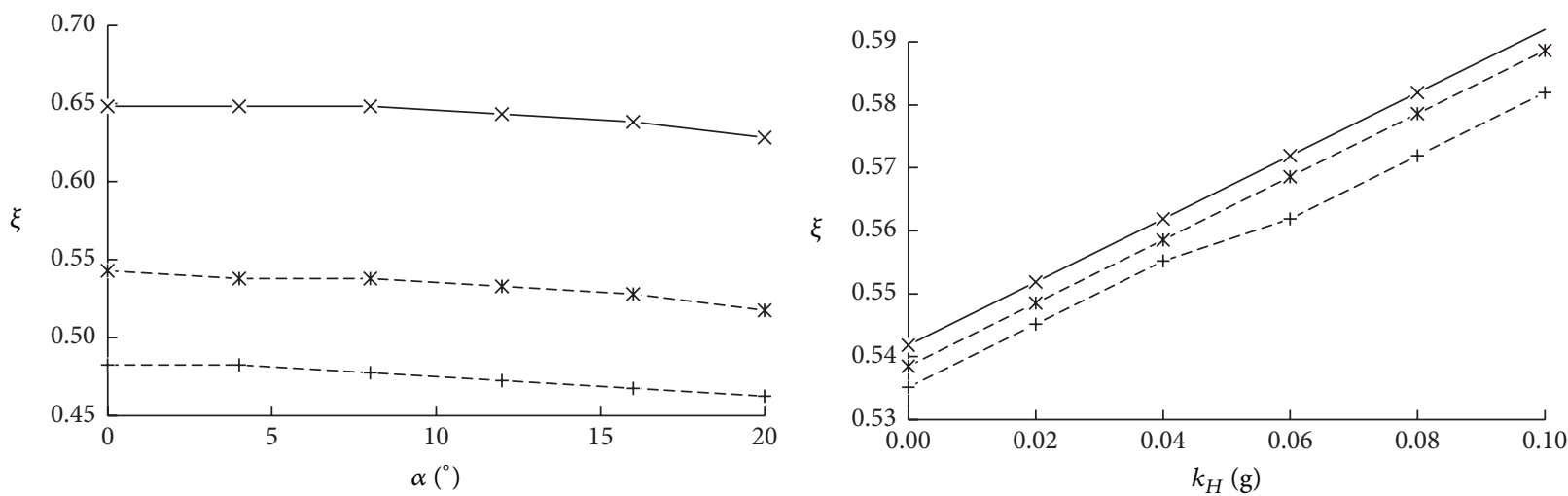

$$
\begin{aligned}
& -x-\beta=0^{\circ} \\
& -x-\beta=10^{\circ} \\
& -+-\beta=20^{\circ}
\end{aligned}
$$

$$
\begin{aligned}
& -\times-k_{V}=0.0 \\
& -*-k_{V}=0.05 \\
& -+-k_{V}=0.1
\end{aligned}
$$

(a) $\alpha$ and $\beta$

(b) $k_{H}$ and $k_{V}$

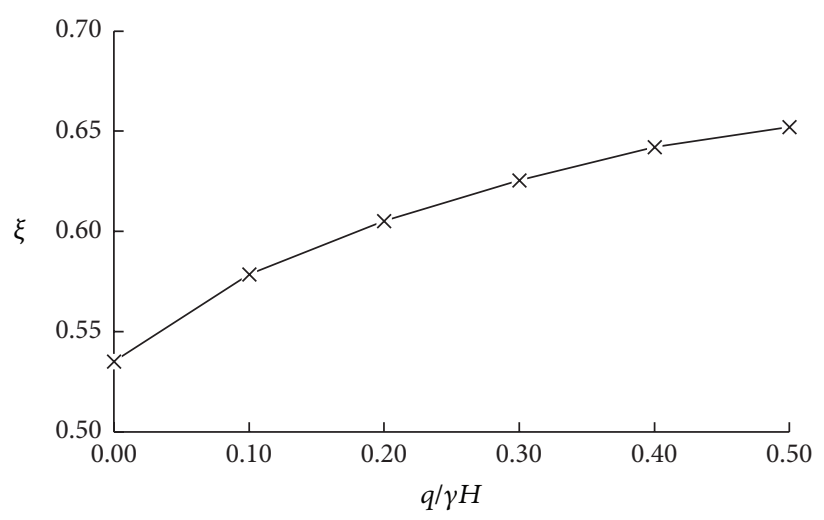

(c) $q$

FIGURE 6: Effects of relevant parameters on $\xi$.

the slope angle $\alpha$ of the retaining wall and the slope angle $\beta$ of backfill surface; $M_{a}$ is increased with the increase of the horizontal seismic coefficient $k_{H}$ and decreased with the increase of the vertical seismic coefficient $k_{V} ; M_{a}$ is increased linearly with the increase of the dimensionless surcharge load $q /(\gamma H)$ of slope surface.

\section{Conclusion}

The seismic active earth pressure is studied in the paper based on the variational limit equilibrium method, and the following conclusions are obtained.

(1) In the framework of limit equilibrium theory, the isoperimetric model of functional extremum regarding the 


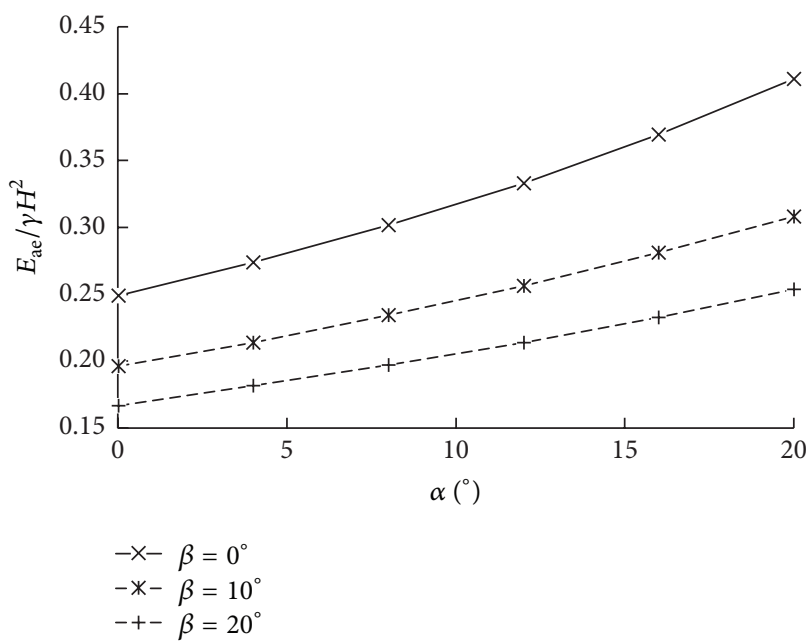

(a) $\alpha$ and $\beta$

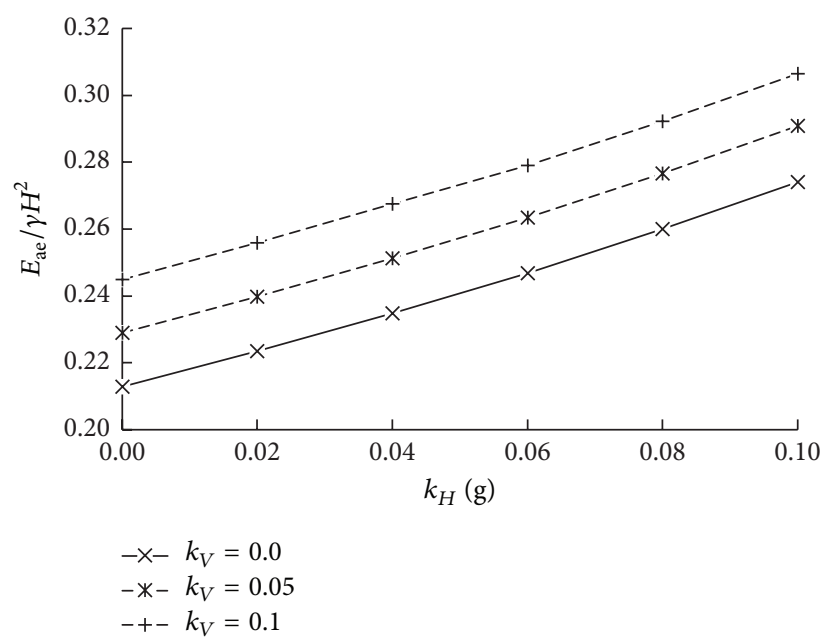

(b) $k_{H}$ and $k_{V}$

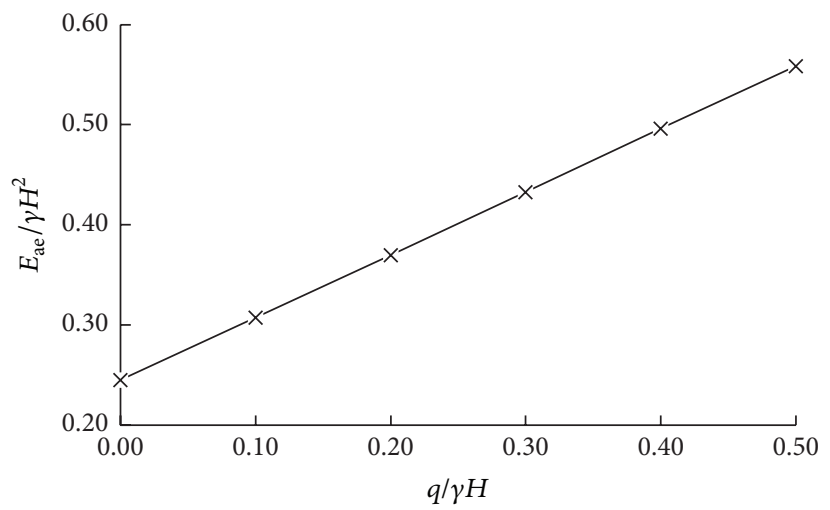

(c) $q$

FiguRE 7: Effects of relevant parameters on $E_{\mathrm{ae}}$.

seismic active earth pressure under general conditions (the retaining wall is inclined and coarse; the backfill is cohesive soil; the backfill surface is a curved surface with nonuniform surcharge) is deduced.

(2) With the introduction of Lagrange multipliers and in combination with the necessary conditions required for the existence of functional extremum, the solution of seismic active earth pressure is transcribed as an optimization problem of two undetermined Lagrange multipliers; with the fminsearch function provided by MATLAB, an optimization solution of two Lagrange multipliers is founded to obtain the magnitude and the action point position of seismic active earth pressure, as well as the shape of slip surface.

(3) With the continuous changes of wall-movement modes of the retaining wall, the position coefficient $\xi$ of the action point of seismic active earth pressure is an interval with lower and upper limit values. When $\xi$ is the lower limit value, the slip surface is a plane and the seismic active earth pressure is minimal. As the action point moves upward, the slip surface becomes a logarithmic spiral surface and its curvature is gradually increased, with the corresponding value of seismic active earth pressure increased in a nonlinear manner. At the upper limit of $\xi$, the seismic active earth pressure is maximal; the minimum and maximum values can be estimated as an interval of the seismic active earth pressure under different wall-movement modes of the retaining wall.

(4) The contrastive analysis shows that when the slip surface is a plane, the solution of seismic active earth pressure obtained by the proposed method is in line with the $\mathrm{M}-\mathrm{O}$ theory solution, verifying the correctness of the proposed method; when the slip surface is a logarithmic spiral surface, the underestimation of the magnitude and the action point position of seismic active earth pressure cause the potential safety hazard of overturning of the retaining wall designed by M-O theory.

(5) The parameter analysis shows that the action point position moves up with the increase of the slope angle $\beta$ of backfill surface, the horizontal seismic coefficient $k_{H}$, and the surcharge $q$ on the backfill surface. However, the vertical seismic coefficient $k_{V}$ and the slope angle $\alpha$ of the retaining wall have little influence on it, so they can be neglected. The seismic active earth pressure $E_{\mathrm{ae}}$ and the overturning moment $M_{a}$ are increased with the increase of the slope angle $\alpha$ of the retaining wall, the slope angle $\beta$ of backfill surface, the 


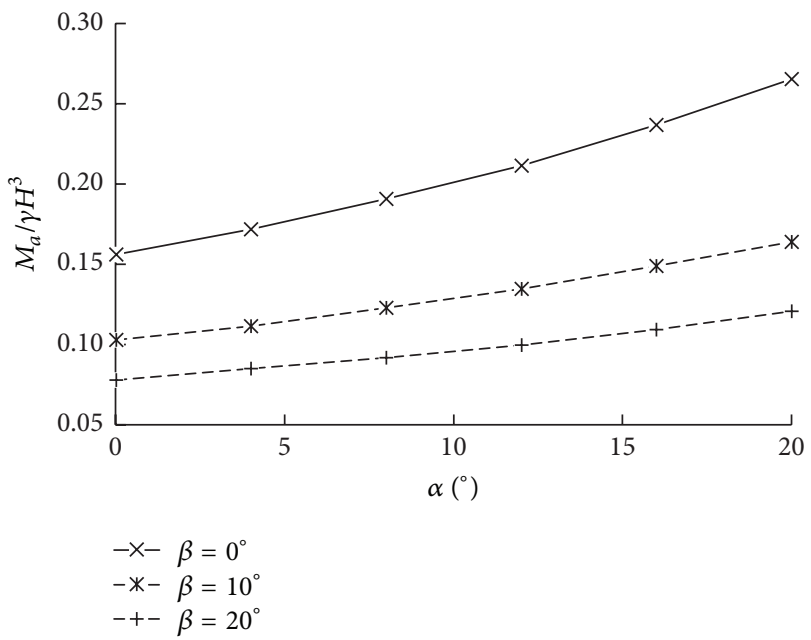

(a) $\alpha$ and $\beta$

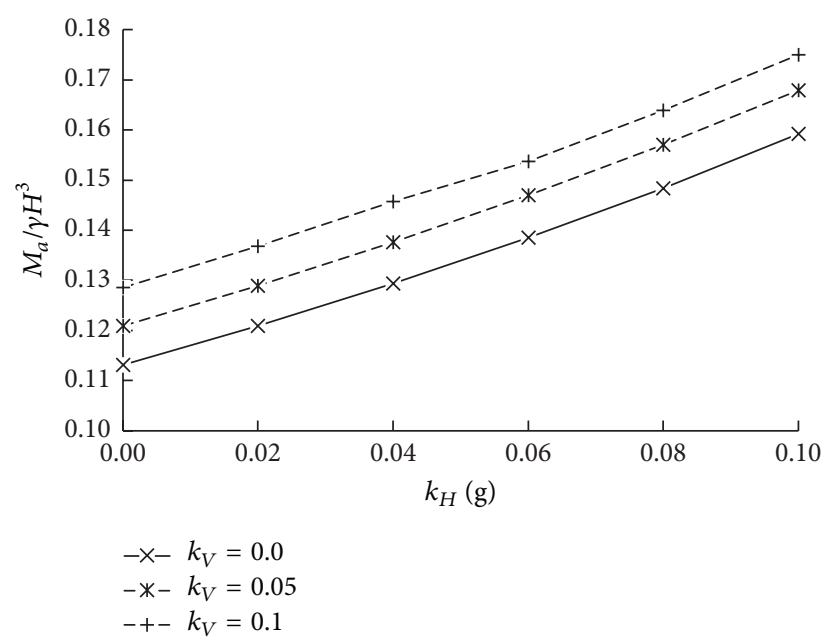

(b) $k_{H}$ and $k_{V}$

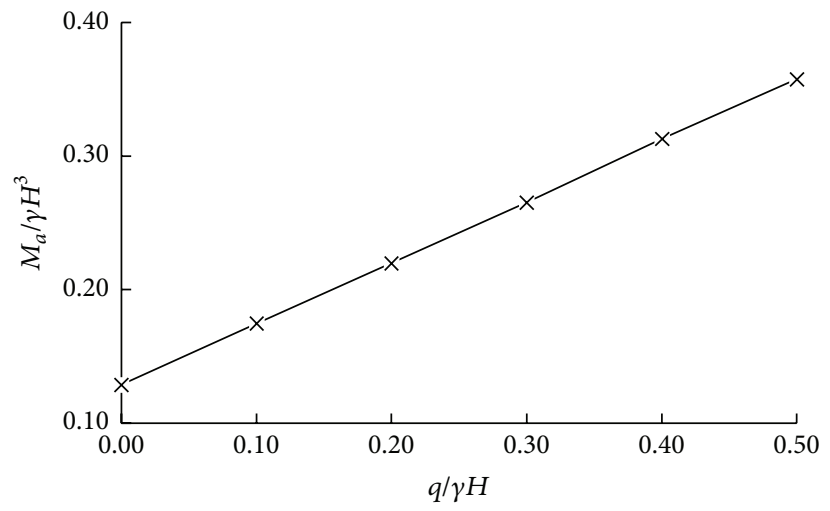

(c) $q$

FIGURE 8: Effects of relevant parameters on $M_{a}$.

horizontal seismic coefficient $k_{H}$, and the surcharge $q$ on the backfill surface and decreased with the increase of the vertical seismic coefficient $k_{V}$.

\section{Competing Interests}

The authors declare that they have no competing interests.

\section{References}

[1] S. Caltabiano, E. Cascone, and M. Maugeri, "Static and seismic limit equilibrium analysis of sliding retaining walls under different surcharge conditions," Soil Dynamics and Earthquake Engineering, vol. 37, pp. 38-55, 2012.

[2] S. Saran and R. P. Gupta, "Seismic earth pressures behind retaining walls," Indian Geotechnical Journal, vol. 33, no. 3, pp. 195-213, 2003.

[3] G. Mylonakis, P. Kloukinas, and C. Papantonopoulos, "An alternative to the Mononobe-Okabe equations for seismic earth pressures," Soil Dynamics and Earthquake Engineering, vol. 27, no. 10, pp. 957-969, 2007.
[4] S. Ghosh and S. Sengupta, "Extension of Mononobe-Okabe theory to evaluate seismic active earth pressure supporting c$\varphi$ backfill," Electronic Journal of Geotechnical Engineering, vol. 17, pp. 495-504, 2012.

[5] M. Yazdani, A. Azad, A. H. Farshi, and S. Talatahari, "Extended 'mononobe-okabe' method for seismic design of retaining walls," Journal of Applied Mathematics, vol. 2013, Article ID 136132, 10 pages, 2013.

[6] Y.-L. Lin, W.-M. Leng, G.-L. Yang, L.-H. Zhao, L. Li, and J.S. Yang, "Seismic active earth pressure of cohesive-frictional soil on retaining wall based on a slice analysis method," Soil Dynamics and Earthquake Engineering, vol. 70, pp. 133-147, 2015.

[7] J. Kopáscy, "Über die Bruchflächen und Bruchspannungen in den Erdbauten," in Gedenkbuch Für Prof. Dr. J. Jáky, K. Széchy, Ed., pp. 81-99, Akadémiaikiadó, Budapest, Hungary, 1955.

[8] J. Kopáscy, "Three-dimensional stress distribution and slip surfaces in earth works at rupture," in Proceedings of the 4th International Conference on Soil Mechanics and Foundations Engineering, vol. 1, pp. 339-342, London, UK, 1957.

[9] J. Kopáscy, "Distribution des contraintesàla rupture, forme de la surface de glissement et hauteur théorique des talus," in Proceedings of the 5th International Conference on Soil Mechanics 
and Foundations Engineering, vol. 2, pp. 641-650, Paris, France, 1961.

[10] W. F. Chen and N. Snitbhan, "On slip surface and slope stability analysis," Soils and Foundations, vol. 15, no. 3, pp. 41-49, 1975.

[11] M. Garber and R. Baker, "Bearing capacity by variational method," Journal of Geotechnical Engineering Division, vol. 103, no. 11, pp. 1209-1225, 1977.

[12] M. Garber and R. Baker, "Extreme-value problems of limiting equilibrium," Journal of the Geotechnical Engineering Division, vol. 105, no. 10, pp. 1155-1171, 1979.

[13] A. J. Spencer and T. C. O’Mahony, "An application of the calculus of variations to rectilinear flow of granular materials," International Journal for Numerical and Analytical Methods in Geomechanics, vol. 9, no. 3, pp. 225-235, 1985.

[14] D. Leshchinsky, "Slope stability analysis: generalized approach," Journal of Geotechnical Engineering, vol. 116, no. 5, pp. 851-867, 1990.

[15] D. Leshchinsky and C.-C. Huang, "Generalized threedimensional slope-stability analysis," Journal of Geotechnical Engineering, vol. 118, no. 11, pp. 1748-1764, 1992.

[16] R. Baker, "Sufficient conditions for existence of physically significant solutions in limiting equilibrium slope stability analysis," International Journal of Solids and Structures, vol. 40, no. 13-14, pp. 3717-3735, 2003.

[17] R. Baker, "Stability chart for zero tensile strength Hoek-Brown materials - the variational solution and its engineering implications," Soils and Foundations, vol. 44, no. 3, pp. 125-132, 2004.

[18] R. Baker, "Variational slope stability analysis of materials with nonlinear failure criterion," Electronic Journal of Geotechnical Engineering, vol. 10, pp. 1-22, 2005.

[19] R. Baker, "A relation between safety factors with respect to strength and height of slopes," Computers and Geotechnics, vol. 33, no. 4-5, pp. 275-277, 2006.

[20] L.-Y. Wu and Y.-F. Tsai, "Variational stability analysis of cohesive slope by applying boundary integral equation method," Journal of Mechanics, vol. 21, no. 3, pp. 187-198, 2005.

[21] Y. M. Cheng, D. Z. Li, N. Li, Y. Y. Lee, and S. K. Au, "Solution of some engineering partial differential equations governed by the minimal of a functional by global optimization method," Journal of Mechanics, vol. 29, no. 3, pp. 507-516, 2012.

[22] X. Li, "Bearing capacity factors for eccentrically loaded strip footings using variational analysis," Mathematical Problems in Engineering, vol. 2013, Article ID 640273, 17 pages, 2013.

[23] A. H. Soubra and R. Kastner, "Influence of seepage flow on the passive earth pressures," in Proceeding of the International Conference on Retaining Structures, pp. 67-76, ICE, Amsterdam, The Netherlands, 1992.

[24] A.-H. Soubra, R. Kastner, and A. Benmansour, "Passive earth pressures in the presence of hydraulic gradients," Géotechnique, vol. 49, no. 3, pp. 319-330, 1999.

[25] O. Puła, W. Puła, and A. Wolny, "On the variational solution of a limiting equilibrium problem involving an anchored wall," Computers and Geotechnics, vol. 32, no. 2, pp. 107-121, 2005.

[26] L. Xinggao and L. Weining, "Study on the action of the active earth pressure by variational limit equilibrium method," International Journal for Numerical and Analytical Methods in Geomechanics, vol. 34, no. 10, pp. 991-1008, 2010.

[27] M. Shaojun, Study on Calculation of Earth Pressure behind Retaining Wall under Static and Dynamic Loads and Its Related Issues, Zhejiang University, Zhejiang, China, 2012 (Chinese). 


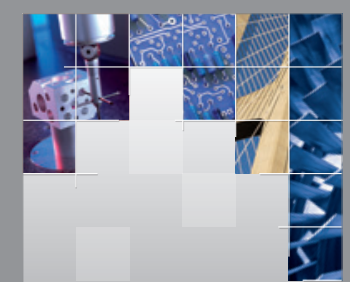

\section{Enfincering}
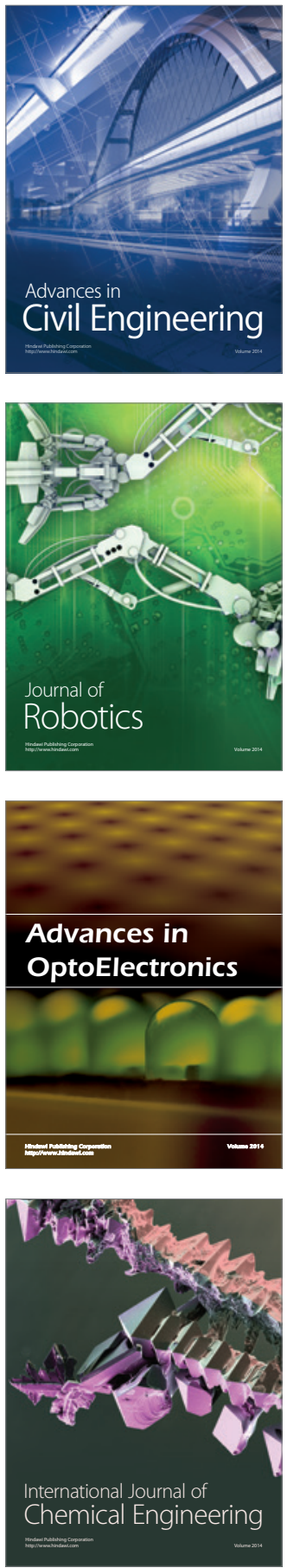

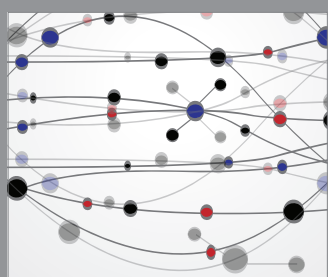

The Scientific World Journal

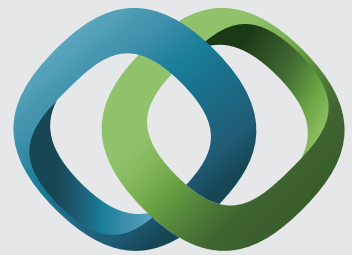

\section{Hindawi}

Submit your manuscripts at

http://www.hindawi.com
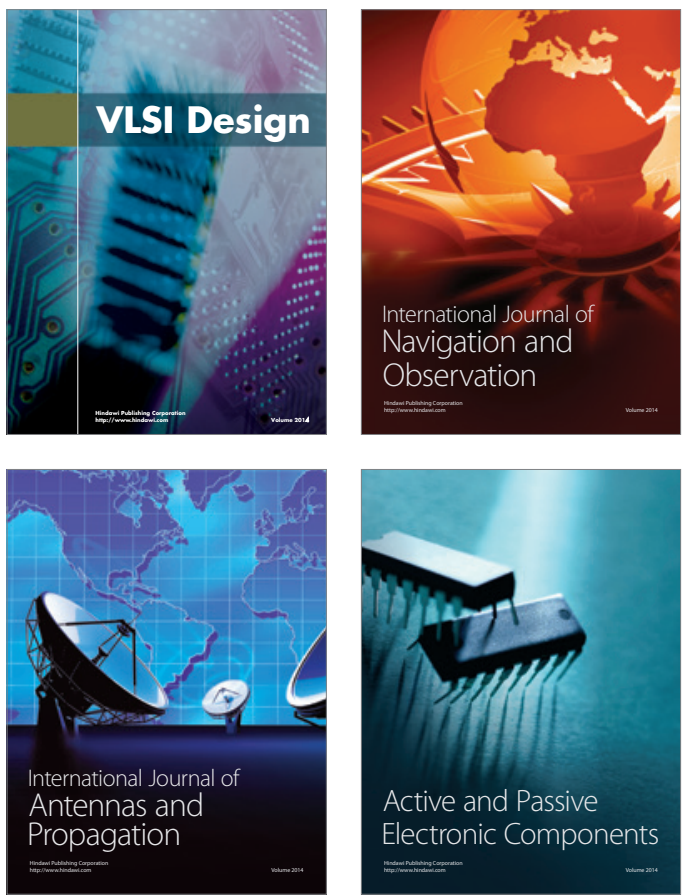
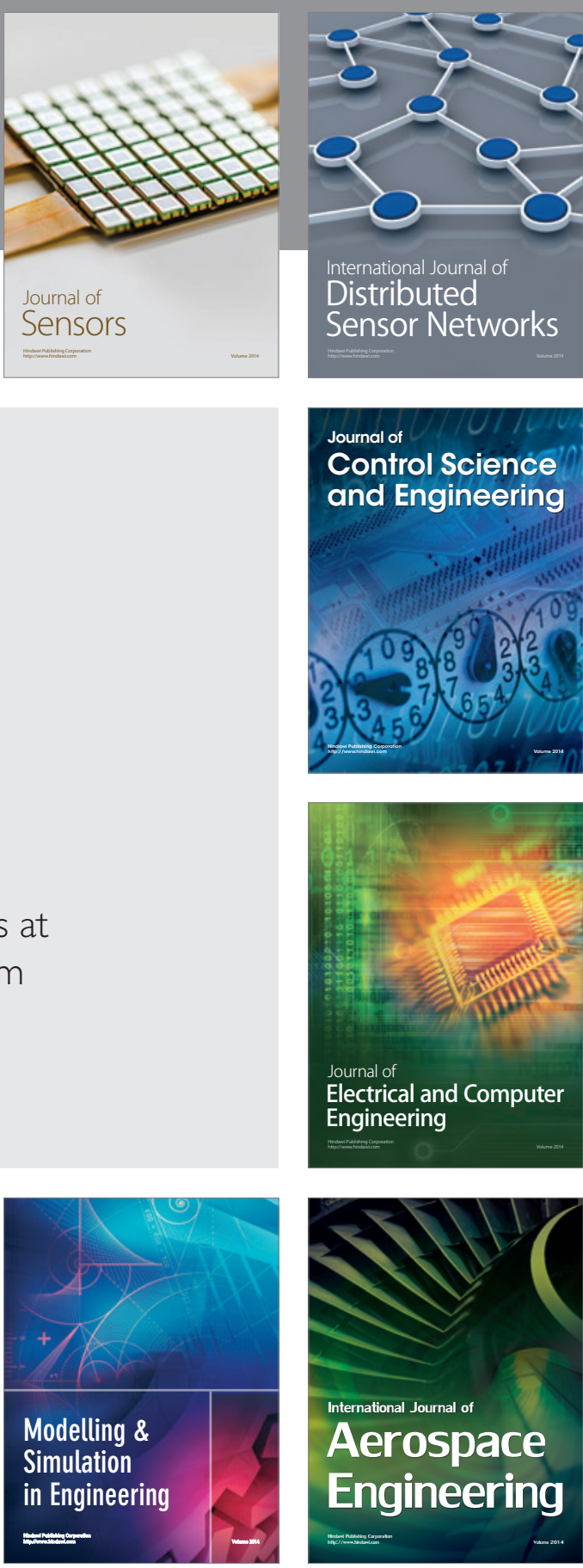

International Journal of

Distributed

Sensor Networks

Journal of

Control Science

and Engineering
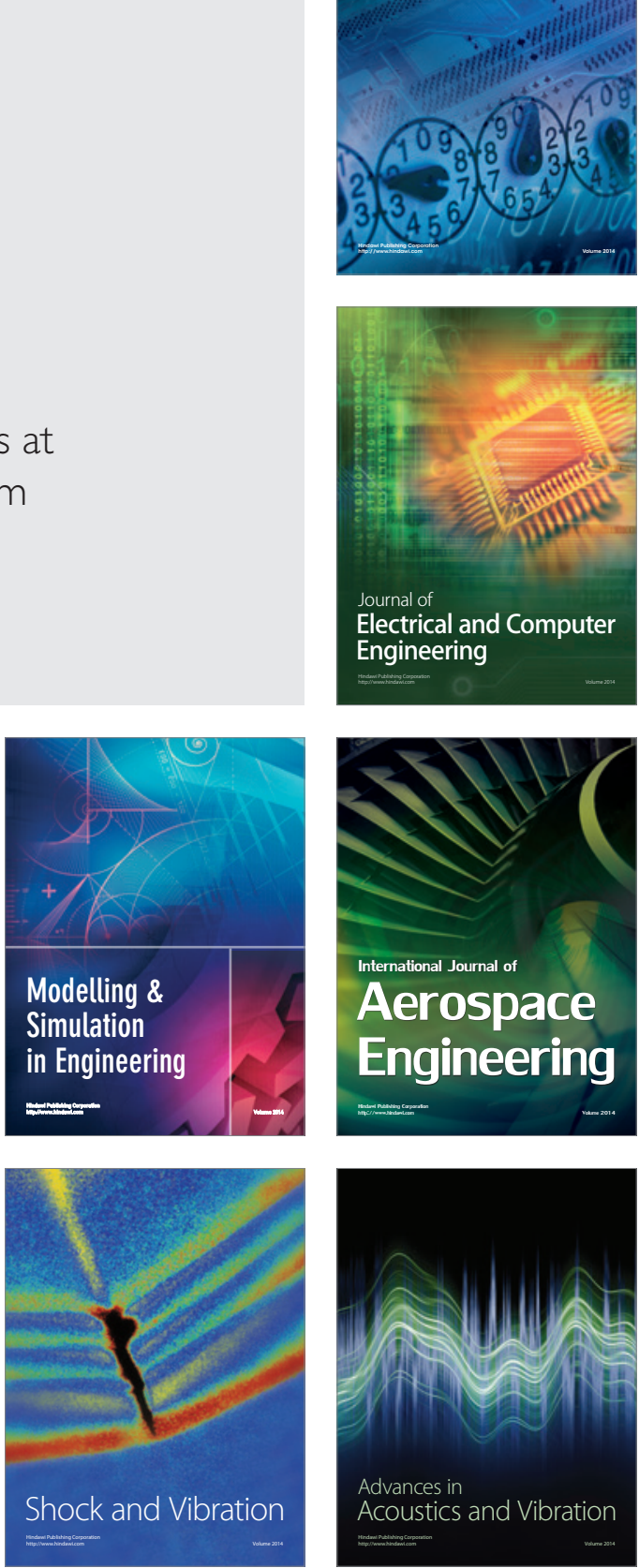